\title{
STUDY ON ECOLOGICAL RISK ASSESSMENT OF GUANGXI COASTAL ZONE BASED ON 3S TECHNOLOGY
}

\author{
Z. Zhong ${ }^{1,2,3, *}$, H. Luo ${ }^{1,2,3}$, Z.Y. Ling ${ }^{1,2,3}$, Y. Huang ${ }^{1,2,3}$, W.Y. Ning ${ }^{1,2,3}$, Y.B. Tang ${ }^{1,2,3}$, G.Z. Shao ${ }^{1,2,3}$ \\ ${ }^{1}$ Geomatics Center of Guangxi, China, People's Republic of \\ ${ }^{2}$ Guangxi Branch of Satellite Surveying and Mapping Application Center, China, People's Republic of \\ ${ }^{3}$ Guangxi Data and Application Center of High Resolution Earth Observation System, China, People's Republic of
}

KEY WORDS: Coastal Zone, Landscape Pattern, Ecological Risk, Remote Sensing, Geographic Information System

\begin{abstract}
:
This paper takes Guangxi coastal zone as the study area, following the standards of land use type, divides the coastal zone of ecological landscape into seven kinds of natural wetland landscape types such as woodland, farmland, grassland, water, urban land and wetlands. Using TM data of 2000-2015 such 15 years, with the CART decision tree algorithm, for analysis the characteristic of types of landscape's remote sensing image and build decision tree rules of landscape classification to extract information classification. Analyzing of the evolution process of the landscape pattern in Guangxi coastal zone in nearly 15 years, we may understand the distribution characteristics and change rules. Combined with the natural disaster data, we use of landscape index and the related risk interference degree and construct ecological risk evaluation model in Guangxi coastal zone for ecological risk assessment results of Guangxi coastal zone.
\end{abstract}

\section{INTRODUCTION}

\subsection{General Instructions}

With the overexploitation and utilization of coastal resources, the bearing pressure of coastal zone gradually increases, and the function of the ecosystem deteriorates seriously $(\mathrm{Li} \mathrm{Z}$.,et al.,2009). All kinds of ecological environment problems ensue and intensify, and the coastal resources and environment are facing serious challenges (Chen S. X.,2008). Basic on landscape pattern, discuss the process and mechanism of the interaction between urban landscape pattern and natural disaster and the difference of the effect of different natural disasters on landscape pattern was analysed (Peng J.,et al.,2014). The ecological risk value of Nansi Lake, with drought, flood and water pollution as ecological risk sources, was obtained by calculated basic on GIS and RS technology (Zhang Y. Z., et al., 2015). The ecological risk of vegetation in Tarim river was assessed quantitatively by using remote sensing technology and fuzzy comprehensive evaluation method (Jiang L Q., et al., 2008).

In this paper, using $3 \mathrm{~S}$ technology to collect, collate and analyze the satellite images of Guangxi coastal zone and combining landscape ecology with regional ecological risk assessment, the landscape classification system of Guangxi coastal zone is set up. To evaluate the level of risk of coastal ecology combining with natural disaster data is of great significance to the harmonious development of the social economy and the ecological environment system of Guangxi coastal zone.

\section{STUDY AREA AND DATA SOURCE}

\subsection{Research scope}

Basic on the coastline in Guangxi, the area extending $10 \mathrm{~km}$ from the coastline to the sea is selected as research buffer, the county administrative region and the coastal waters covered by the buffer are selected as research scope and the coastal land is selected as the main research area, as shown in the figure 1.

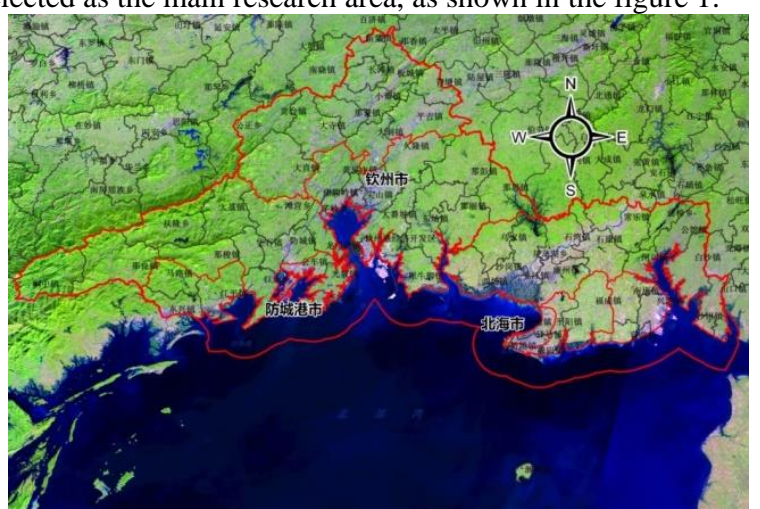

Figure 1. Regional map of Guangxi coastal zone

\subsection{Data Source}

2.2.1 Satellite remote sensing data: The satellite remote sensing data of 2000 and 2015 used in this paper are from china science geospatial data cloud. The coastal region of Guangxi is affected by the subtropical monsoon climate the whole year, and it is cloudy and rainy. The remote sensing image in autumn and winter is selected as the research data because of good visibility and high availability. As shown in Table 1.

\begin{tabular}{|c|cc|cc|}
\hline \multirow{2}{*}{ Years } & \multicolumn{2}{|c|}{ TM } & \multicolumn{2}{c|}{ GF2 } \\
\cline { 2 - 5 } & 124045 & 125045 & E & N \\
\hline 2000 & $2000 / 11 / 23$ & $2000 / 8 / 10$ & $\backslash$ & $\backslash$ \\
2015 & $2015 / 9 / 30$ & $2015 / 10 / 23$ & $107^{\circ} 28^{\prime}-$ & $20^{\circ} 26^{\prime}-$ \\
& & & $109^{\circ} 47^{\prime}$ & $22^{\circ} 47^{\prime}$ \\
\hline
\end{tabular}

Table 1. Satellite remote sensing imaging schedule

\footnotetext{
* Corresponding author

Email address: 215557511@qq.com (Z. Zhong)
} 
2.2.2 Basic geographic information data: The 1:250,000 basic geographic information data of the three inshore cities of Beihai, Qinzhou and Fang Chenggang in Guangxi, using the upto-date remote sensing images to supply and collect information of highways, railways and ports which lastly constructed along the coast, forming a basic administrative division map of Guangxi coast; Data of 1:10,000 National Geographic Survey of the three coastal cities in Guangxi in 2015 are provided by Guangxi Geographic Information and Mapping Bureau.

2.2.3 natural disaster data: The data used in this paper, such as meteorological drought data from 1961 to 2015, tropical cyclone data points from 1949 to 2011 and flood disaster data in study area from 1983 to 2015, are all from china meteorological data network.

\section{RESEARCH METHOD}

\subsection{Ecological risk assessment model}

To some extent, the degree of risk and vulnerability can be expressed to some extent in the area. The degree of risk is calculated based on the statistical data of disasters in the region over the years. The intensity of disaster which is predicted value is related to the frequency. The degree of vulnerability is the potential of the maximum loss of the regional ecosystem under the threat of disaster and is current value. Based on the research content and the actual situation, the relationship between the landscape loss and the ecological risk is established, Risk degree $=$ risk level $\times$ vulnerability degree. It forms the Evaluation model of Ecological risk in Guangxi Coastal Zone. See formula (1) for details.

$$
E R I=\sum_{i=1}^{n} w_{i} E R_{i}
$$

ERI indicates comprehensive risk degree of risk source; $\mathrm{n}$ indicates risk source numbers; $w_{i}$ indicates risk level of class I risk source. See formula (2) for details.

$$
E R_{i}=R I \times F_{i}
$$

$E R_{i}$ Shows ecological risk which class I risk source brought out in research area; RI shows ecological vulnerability on research area; $F_{i}$ shows risk level of risk source.

\subsection{Technical route}

According to the classification of national land-use present situation, the landscape classification system of Guangxi coastal zone is established ; the remote sensing interpretation of the rules of image classification is used to obtain the landscape classification results, and the indexes of landscape pattern are calculated for getting landscape loss index based on landscape pattern; arranged natural disaster data and obtained natural disaster risk level through spatial interpolation and classification; synthesized landscape ecological loss index and natural disaster risk level, basing on regional ecological risk model, how ecological risk assessment model of Guangxi coastal zone is formed, also the comprehensive ecological risk assessment results of the study area are obtained, as shown in figure 2 .

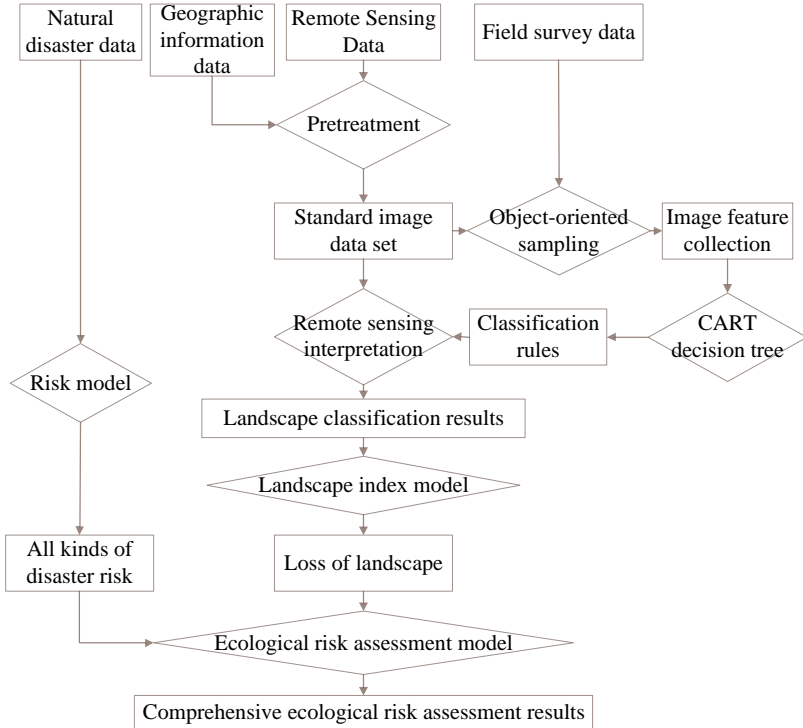

Figure 2. Ecological Risk Assessment Technology Roadmap of Coastal Areas in Guangxi

\section{RESULT AND ANALYSIS}

\subsection{Landscape Index}

The landscape loss index refers to the degree of loss of the ecosystem when it is threatened by an uncertain source of risk. The vulnerability of the natural attributes of various landscape ecosystems is the combined result of the landscape structure of the ecosystem and various types of landscape vulnerability.

The landscape loss index of Guangxi coastal zone had increased gradually and the level of landscape loss index had decreased from east to west, from inland to sea during 2000 to 2015.

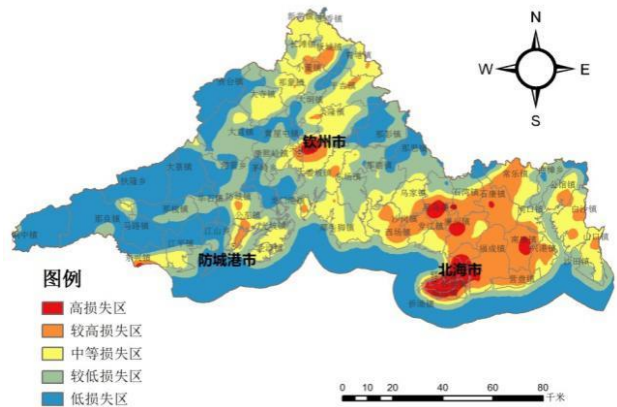

Figure 3. Spatial distribution of landscape loss index in Guangxi Coastal Zone in 2000

\subsection{Risk of natural disasters}

The source of natural disasters risk had act on the receptors of the landscape ecosystem through direct or indirect methods, causing them to suffer a certain degree of damage. In this paper, the frequency and severity of major natural disasters such as droughts, floods, and tropical cyclones have been collected and used to calculate the risk of natural disasters then to reflect the impact of natural disasters on landscape ecology.

4.2.1 Risk of drought disaster: Beihai City, Hepu County, and northwest of Qinzhou City have the highest risk of drought disaster. Qinzhou City and Fangchenggang City are relatively low. The characteristic of the scatter of the risk of drought disaster is high in east and low in west, as shown in Figure 4. 


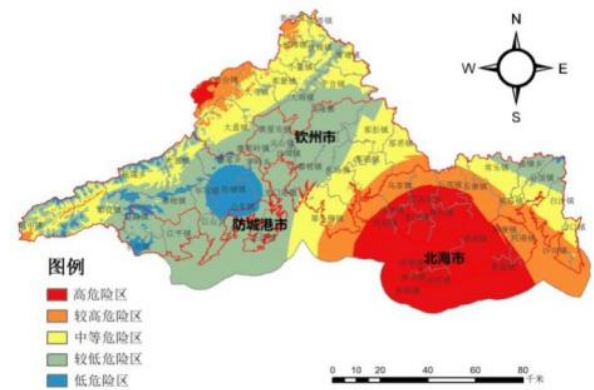

Figure 4. Distribution of Annual Drought Risk in Coastal Areas of Guangxi

4.2.2 Risk of flood damage: The risk of flood damage in the coastal zone of Guangxi is high in the northeast, inland and low in the southwest, coast, See Figure 5 for details.

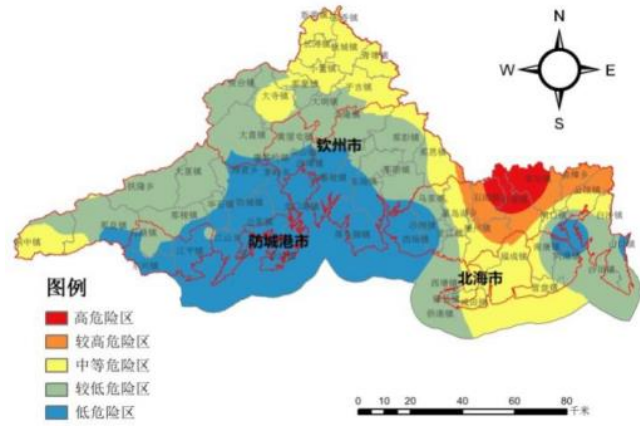

Figure 5. Annual Flood Hazard Distribution in Coastal Areas of Guangxi

4.2.3 Risk of tropical cyclone disaster:Risk of the tropical cyclone disaster is high in the southeast, coast and low in the northwest, inland, See Figure 6 for details.

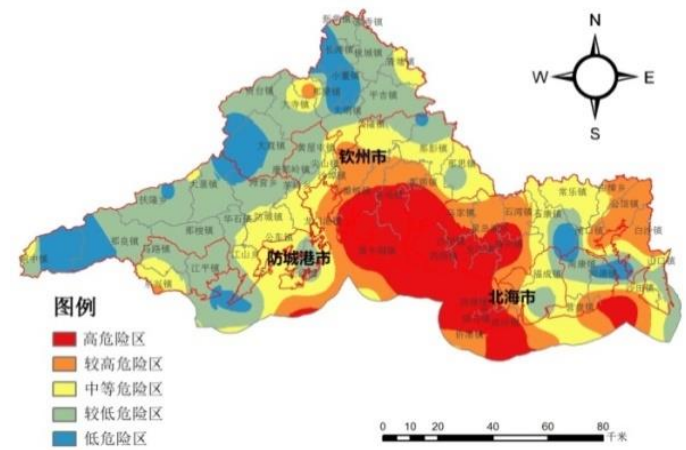

Figure 6. Distribution of tropical cyclone hazards in Guangxi coastal zone

\subsection{Comprehensive Ecological Risk Assessment}

Combining with the scope, duration and degree of damage of disasters over the years, weight of various risk sources can be distinguished into drought disaster $=0.3$, flood disaster $=0.2$, tropical cyclone hazard 0.5. The risk degree of various risk sources is standardized. According to the results of formula (1), the maximum value of comprehensive ecological risk index of Guangxi coastal zone is 0.78 , and the lowest value is 0.017.The comprehensive ecological risk in the coastal zone of Guangxi is divided into five risk areas with high, high, medium, low and low levels by method of natural breaks class, which is shown in Table 2 for comprehensive evaluation.

\begin{tabular}{|c|c|}
\hline grade & Risk value range \\
\hline low risk & {$\left[\begin{array}{ll}0.017, & 0.11\end{array}\right]$} \\
Lower risk & $(0.11,0.19]$ \\
Moderate risk & $(0.19,0.28]$ \\
Higher risk & $\left(\begin{array}{ll}0.28, & 0.42\end{array}\right]$ \\
high risk & $(0.42,0.78]$ \\
\hline
\end{tabular}

Table 2. Comprehensive Ecological Risk Classification Table

The comprehensive ecological risk in Guangxi coastal zone is characterized by the distribution of east high and west low risk, in which the high risk area is mainly concentrated in the Beihai urban area with a total area of 589.9 square kilometers, and low risk area is mainly distributed in the west of Fangchenggang City. The total area is 4719.09 square kilometers, see figure 7 for details.

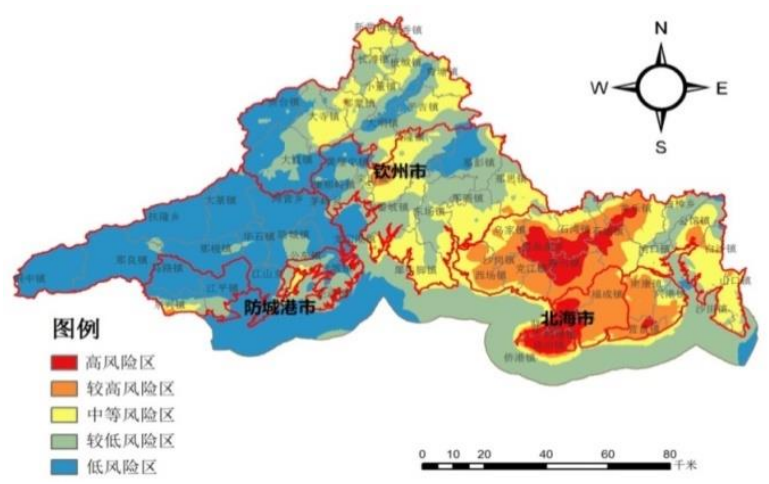

Figure 7. Distribution of comprehensive ecological risk grades in Guangxi coastal areas

\section{CONCLUSION}

(1) Remote sensing image has been quickly interpreted by combining $3 \mathrm{~S}$ technology and CART decision tree algorithm to gain landscape pattern.

(2) Based on loss index of degree of landscape risks and degree of natural disasters of landscape pattern, model of ecological risk assessment can be built.

(3) Comprehensive ecological risk of Guangxi coastal zone decline from east to west. High and less high risk area mainly concentrate in urban area of Beihai city and Hepu County which have a high population density, farming, fast development of city construction. That explains that human activities can bring a big effect to the ecosystem in coastal zone. Low and lower risk area mainly concentrate in Fangcheng district of Fang Chenggang city which have low population density, high level of forest coverage, slower development of city construction. It explains less human activities and high level of forest coverage affects the ecosystem in coastal zone much less.

\section{REFERENCES}

Li Z., Tan L.,2009. Progress on the Conservation of Biodiversity of Coastal District. Chinese Agricultural Science Bulletin, 25(12):260-262.

Chen S. X. , 2008. The integrated management of coastal zone resources supported by Remote sensil and GIS. Science \& Technology Information, (20):57-108. 
Peng J., Liu Y., Pan Y., et al., 2014. Study on the Correlation between Ecological Risk due to Natural Disaster and Landscape Pattern-Process: Review and Prospect. Advances in Earth Science, 29(10):1186-1196.

Zhang Y. Z., Xie X. P.,2015. Regional ecological risk assessment in Nansi Lake based on R S and GIS. Acta Ecologica Sinica, 35(5):1371-1377.

Jiang L. Q., Shu C. Q., Lei J. R., et al.,2008. Study on the Methods of Ecological Risk Fussy Assessment Based on Remote Sensing and Geographical Information System. Journal of China West Normal University, (03):313-318. 